\title{
A formação de professores no curso de Licenciatura em Computação: um relato das práticas educacionais de iniciação a docência.
}

\author{
Cristina C. Almeida ${ }^{1}$, Luciano P. Carvalho ${ }^{1}$ \\ ${ }^{1}$ Instituto Federal de Educação, Ciência e Tecnologia do Sul de Minas Gerais \\ IFSULDEMINAS - Campus Machado \\ Rodovia Machado Paraguaçu - Km 03 - 37.750-000 - Machado - MG - Brasil \\ \{cris, lucianop\}@mch. ifsuldeminas.edu.br
}

\begin{abstract}
The Bachelor's Degree in Computing IFSULDEMINAS - Campus Machado seeks to empower future educators in the area of computer networks to act in public and private education. For this, the course seeks to provide future teachers in computer vision technology so it can perform its activities with professionals from other areas, which may integrate computer learning the content of other sciences. Significant contributions have been given through the practice of education as a curriculum component and the participation of students in PIBID / CAPES - Institutional Scholarship Program for New Teachers.
\end{abstract}

Resumo. O curso de Licenciatura em Computação do IFSULDEMINAS Campus Machado busca capacitar futuros educadores na área de informática para atuação nas redes de ensino público e privado. Para isto, o curso procura oferecer ao futuro professor uma visão tecnológica em computação para que possa desempenhar suas atividades com profissionais de outras áreas, as quais podem integrar a computação ao aprendizado dos conteúdos de outras ciências. Contribuições significativas têm sido dadas através das práticas de ensino como componente curricular e pela participação dos alunos no PIBID/CAPES - Programa Institucional de Bolsas de Iniciação à Docência.

\section{Introdução}

O fato da informática estar inserida em grande parte das mais variadas atividades profissionais determina, em certa medida, que os profissionais saibam utilizar efetivamente o computador e demais recursos inovadores para que possam atuar satisfatoriamente no mercado de trabalho. Consequentemente, a estruturação de currículos nestas áreas requer a inclusão de competências, habilidades e bases tecnológicas da área de Informática, com graus de profundidade diretamente relacionados à maior ou menor dependência desta ao processo produtivo, objeto da formação do futuro profissional. Ressalta-se que o uso das tecnologias e a reestruturação 
das práticas educativas podem instituir mudanças significativas na forma de dimensionar os conteúdos curriculares e as formas de acesso às informações que serão trabalhadas.

Conforme portal do Ministério da Educação, especificamente o sistema e-MEC criado para fazer a tramitação eletrônica dos processos de regulamentação de cursos e acessível através do endereço http://emec.mec.gov.br/, é possível constatar que existem poucos cursos de Licenciatura em Computação no Brasil e inversamente proporcional a este número está o fato da crescente demanda mercadológica oriunda da inclusão de disciplinas de computação no nível de ensino médio e cursos de capacitação profissional, exigindo educadores qualificados e preparados para atuar nessa área. Paralelamente a esta demanda surge, no contexto dos cursos técnicos integrados ao ensino médio, a necessidade de avaliação contínua das formas de integração possíveis entre a extensa matriz de disciplinas dos cursos desta modalidade e uma forma de implantação de atividades interdisciplinares que envolvam a computação e as outras áreas do saber.

Outro fato que justificou a dedicação da equipe pedagógica do Instituto Federal de Educação, Ciência e Tecnologia do Sul de Minas Gerais (IFSULDEMINAS) Campus Machado na elaboração do Projeto Pedagógico do Curso (PPC) de Licenciatura em Computação pode ser percebido nos registros de falta de educadores licenciados em computação nos últimos concursos para docentes realizados na região. Pouquíssimos candidatos inscritos eram portadores do título de Licenciatura na área, enfatizando assim a falta de profissionais habilitados para a prática pedagógica em computação e forçando a aprovação dos profissionais com formação em Bacharelado e outros níveis relacionados à área. Os cursos de nível superior em Ciência da Computação, Sistemas de Informação e Tecnólogo em Processamento de Dados, apesar de conter excelente grade curricular de disciplinas da área de computação e pesquisa científica, não habilitam seus egressos com conhecimentos específicos que lhes permitam atuações suficientemente satisfatórias na prática pedagógica em computação.

Para a melhoria da qualidade do ensino, por meio da capacitação de profissionais que se tornarão habilitados para a docência, percebe-se a necessidade de direcionar o conhecimento dos licenciados em computação para o desenvolvimento de práticas pedagógicas nas quais a demanda por educadores com habilidades inerentes a formação de professores e habilitação técnica necessária possa ser atendida.

\section{Objetivos}

Este artigo pretende demonstrar, através de um estudo de caso, as possibilidades de oferecer através do curso de Licenciatura em Computação a formação técnica e pedagógica através da vivência proporcionada pela realização de atividades práticas de ensino e da experiência adquirida com a participação no PIBID (Programa Institucional de Bolsas de Iniciação à Docência), financiado pela CAPES (Coordenação de Aperfeiçoamento de Pessoal de Nível Superior), visando a implantação da tecnologia da informação nas escolas de educação básica para auxílio aos docentes de Física e Matemática com o trabalho num ambiente construtivista no qual o aluno poderá construir seu conhecimento auxiliado pelos recursos computacionais e outras modalidades de comunicação didática. 
O artigo pretende ainda propor à comunidade escolar uma ação cultural na prática, visando tornar dinâmica a mediação da sociedade da informação e do conhecimento, assim como sua utilização através de ações criativas e inovadoras, que despertem o interesse de uma comunidade escolar rodeado por uma realidade muitas vezes problemática.

\section{Fundamentação teórica}

Freire (1997) apresenta em sua obra Pedagogia da Autonomia "a boniteza de ser gente", "a boniteza de ser professor": "ensinar e aprender não podem dar-se fora da procura, fora da boniteza e da alegria". O autor chama a atenção para a essencialidade do componente estético da formação do educador. O saber profissional do professor bem como sua experiência de atitudes, de reflexão, de pesquisa e de intervenção, deve ser considerado sob uma ótica de determinada totalidade e não reduzido a certas competências técnico-profissionais.

Segundo Lévy (1999), a técnica é produzida dentro de uma cultura e uma sociedade encontra-se condicionada por suas técnicas. Para o autor, enquanto muitas vezes discute-se as possíveis formas de utilização de uma tecnologia, algumas maneiras de utilizá-la já se impuseram. Neste contexto, a cibercultura define-se como um conjunto de técnicas materiais e intelectuais, de práticas, de atitudes, de modos de pensamento e valores que se desenvolvem juntamente com o crescimento do universo de informações que este ambiente abriga assim como os seres humanos que alimentam e navegam neste ambiente.

No ambiente educacional, a inserção das Tecnologias da Informação e Comunicação (TIC's) pode provocar mudanças mas deve ser realizado um esforço, conforme Zambalde (2002), objetivando diminuir os impactos para que a escola possa ser atualizada frente às inovações tecnológicas. Para Lévy (1999) a metáfora do impacto é inadequada, pois não se compara a tecnologia a uma pedra nem a um projétil que pode causar danos irreversíveis e a cultura ou a sociedade não podem ser comparadas a alvos vivos. Para este autor, deve haver uma estrutura relacional não somente entre a tecnologia e a cultura e sim entre todos os atores humanos que a inventam e utilizam de diferentes formas. Para Kenski (2010) a inserção das tecnologias na perspectiva educacional requer uma "reflexão profunda sobre a escola e o ensino que ela oferece; sobre as formas de avaliação da aprendizagem e do próprio processo pedagógico em ação".

Conforme Alves e Zambalde (2002), os educadores precisam estar preparados para a nova fase da educação na qual é exigida a capacidade de interpretar, compreender, assimilar e processar um número cada vez maior de informações e os profissionais da educação precisam estar atentos para não retrocederem a detentores do conhecimento para simples transmissão aos alunos passivos e devem tornar-se lançadores de desafios e participantes ativos do processo educacional.

Neste sentido, Gadotti (2004) descreve o professor como um mediador do conhecimento, um aprendiz permanente frente ao aluno que tem papel de sujeito de sua própria formação. Ênfase deve ser dada aos saberes e neste contexto identificam-se alguns fatores principais: o gosto de aprender; o prazer em ensinar e o amor ao discente. Para Gadotti (2003), somente aprendemos quando o que aprendemos é "significativo" 
para nós e nos envolvemos profundamente no que aprendemos. Para Lévy (1999) quanto mais os processos de inteligência coletiva se desenvolvem melhor é a apropriação das alterações técnicas por indivíduos e grupos e consequentemente menores são os efeitos da exclusão resultante da aceleração do movimento tecnossocial. Neste sentido, a inteligência coletiva proposta pela cibercultura pode ser considerada um veneno para aqueles que dela não participam e um remédio para aqueles que mergulham em seus turbilhões.

Segundo Kenski (2010) a escolha entre os meios tecnológicos ou mídias mais adequadas para desenvolver o ensino é uma decisão que cabe à equipe de professores e alunos da escola de modo a alcançar os objetivos previstos. Este pode ser considerado, do ponto de vista de decisão sobre o projeto pedagógico da escola, um dos fatores mais decisivos para o sucesso do uso das tecnologias na educação de modo que os professores sejam conhecedores dos procedimentos técnicos necessários para sua utilização e possam criar outras possibilidades pedagógicas através da integração destes meios com o processo de ensino.

Para Gadotti (2003), o caráter reflexivo da função docente tem se realçado como algo muito novo. Entretanto, não há teoria da educação que não defenda expressamente a necessidade da reflexão na prática do professor. Verbalizar o termo "professor reflexivo" pode ser considerado um ato redundante. Não basta para o educador ser reflexivo. É necessário dar sentido à reflexão. Este conceito torna-se instrumento para a melhoria do que é específico em sua profisssão que tem como diferencial a construção e a impregnação de sentido a cada ato da vida cotidiana. No entanto, esta reflexão deve ser crítica.

Segundo Alves e Zambalde (2002), é obrigação dos educadores, enquanto mediadores do conhecimento e formadores de seres pensantes, críticos e autônomos, trabalhar para que a nova geração possa atender as necessidades do mercado de trabalho emergente.

Em todo processo de formação continuada é necessário ter maior integração entre os espaços sociais (tanto domiciliar, quanto escolar, empresarial, etc.) visando à preparação do aluno para conviver da melhor forma na sociedade do conhecimento. Como previsto por Mcluhan (1974), "o planeta tornou-se a nossa sala de aula e o nosso endereço. $O$ ciberespaço rompeu com a ideia de tempo próprio para a aprendizagem. $O$ espaço da aprendizagem é aqui, em qualquer lugar; o tempo de aprender é hoje e sempre".

Kenski (2010) considera como desafio para as instituições de ensino de todos os níveis as mudanças nas estruturas e na lógica dos conhecimentos que consequentemente necessitam de concepções inovadoras para as abordagens disciplinares, novas metodologias e novas perspectivas para a ação docente.

Ao adotar o uso da Tecnologia da Informação (TI) em sua disciplina, segundo Lucena (1994), o professor deve estar preparado para utilizar programas que estimulem o desenvolvimento das habilidades cognitivas dos alunos oferecendo-lhes situações que permitam a transferência de conhecimento visando a solução de problemas. 


\section{Metodologia}

Este artigo configura-se como um estudo de caso descritivo conceituado a partir das experiências da comunidade escolar do curso de Licenciatura em Computação do IFSULDEMINAS - Campus Machado. Foram analisados dois fatos específicos: a realização das Práticas de Ensino como Componente Curricular (PCC's) e a participação dos alunos no PIBID.

O curso de Licenciatura em Computação funciona no período noturno e para o segundo semestre de 2012 contará com quatro turmas: $2^{\circ}, 4^{\circ}, 5^{\circ}$ e $7^{\circ}$ períodos de um total de oito períodos para conclusão normal do curso. $\mathrm{O}$ quadro docente conta com vinte professores incluindo os que já atuaram em períodos anteriores. Deste total, $65 \%$ possuem Mestrado e 15\% Doutorado.

As PCC's do curso de Licenciatura em Computação do IFSULDEMINAS Campus Machado buscam oferecer aos alunos a oportunidade de conhecer e questionar a entidade escolar, o funcionamento e as atividades desenvolvidas neste ambiente bem como no seu entorno. Estas práticas de ensino exigem a cooperação de todos os docentes do curso na medida em que abordam os assuntos relacionados à formação dos futuros professores. Esta cooperação torna-se possível devido à experiência do corpo docente conforme apresentado pelos índices de formação profissional do quadro de professores.

Faz-se necessária a integração entre as diversas disciplinas da matriz curricular do curso, através das quais são selecionadas unidades que permitam o desenvolvimento dos saberes necessários para a formação dos licenciandos, que são acompanhados e avaliados pelos docentes. Para realização das práticas de ensino, as disciplinas promovem articulações pedagógicas e técnicas através de projetos, oficinas temáticas e outras atividades, tanto nos tópicos específicos de cada disciplina quanto em temáticas emergentes.

Como a matriz curricular do curso conta com disciplinas do núcleo básico, do núcleo profissional e do núcleo específico muitas são as oportunidades de dinamizar as práticas de ensino. Como possibilidades de execução destas atividades foram realizadas desde o início do curso, entre outras, as seguintes práticas de ensino:

- definição de métodos de avaliação das disciplinas de Organização de Computadores, Sistemas Operacionais e Redes de Computadores através da criação, pelos discentes, de roteiros com questões avaliativas em diferentes formatos (questões dissertativas, relacionamento entre colunas, questões objetivas);

- simulação de prática pedagógica interdisciplinar entre as disciplinas de Lógica Matemática e Organização de Computadores através de jogo pedagógico de perguntas e respostas relacionadas aos tópicos abordados pelas disciplinas;

- apresentações lúdicas (peças teatrais, músicas) criadas pelos discentes do curso sobre os conceitos trabalhados na disciplina de Redes de Computadores;

- preparação de material didático sobre Sistemas Operacionais de forma a abranger de forma pedagógica e criativa a história dos sistemas operacionais, os tipos de licença, as principais características, o tratamento de processos, o 
gerenciamento de memória, o sistema de arquivos, as recomendações de uso, os exemplos de telas e/ou comandos;

- experiências práticas com softwares educacionais, lousa eletrônica, simulações, experiências de gestão, organização de planos pedagógicos, capacitação de docentes entre outras várias modalidades, tendo como foco o ensino da informática e suas tecnologias;

- desenvolvimento de diferentes metodologias, como um novo compilador, material didático ilustrado, vídeo-aula, para o ensino de Lógica de Programação;

- simulação de aulas com temas interdisciplinares para o nível Ensino Médio utilizando as tecnologias de informação e comunicação.

Considerando a outra dimensão a ser avaliada neste estudo de caso, a coleta de dados sobre as contribuições do PIBID para a formação de professores no curso de Licenciatura em Computação foi realizada através de reuniões periódicas entre a coordenação de área do projeto, os professores colaboradores no campus Machado, os professores supervisores da área de Matemática e Física nas duas escolas estaduais atendidas e os vinte alunos bolsistas do curso de licenciatura. A observação realizada durante o segundo semestre de 2011 e primeiro semestre de 2012 foi do tipo participativa através da qual houve interação direta entre os membros do grupo estudado.

O projeto institucional do PIBID no IFSULDEMINAS contempla a formação de professores no sul de Minas Gerais por meio da concessão de bolsas de iniciação a docência e de verbas de custeio a elas vinculadas. Com a implementação do projeto institucional do PIBID espera-se promover a formação continuada dos professores das escolas públicas estaduais que atuam como supervisores de área do projeto, permitir a formação inicial dos alunos dos cursos de licenciatura participantes do projeto, redimensionar as práticas de estágio supervisionado dos cursos de licenciatura, favorecer o desenvolvimento das práticas interdisciplinares no Ensino Fundamental e Médio e consequentemente buscar aumentar o interesse dos alunos nas disciplinas das áreas do projeto e aumentar o interesse dos alunos das licenciaturas pelo trabalho docente. Esse projeto institucional contempla as Licenciaturas em Ciências Biológicas (campus Machado e Inconfidentes), Matemática (Inconfidentes) e Computação (Machado).

No caso específico analisado para elaboração deste artigo, o PIBID Subprojeto Computação estabeleceu uma série de atividades em seu cronograma. Inicialmente foram selecionados, através de elaboração de carta de intenções e entrevista, os alunos bolsistas do curso de Licenciatura em Computação e os professores supervisores das escolas estaduais conveniadas e atendidas pelo projeto.

Para enfatizar o vínculo entre a Computação e a Matemática, os alunos bolsistas foram incentivados a estudar o tema "Sem Matemática não existe Computação" e apresentar a todo o grupo do subprojeto, de forma criativa, a relação entre estas disciplinas.

Os alunos bolsistas passaram a frequentar as aulas de Física e Matemática nas escolas estaduais, sob a orientação dos professores supervisores, para poder analisar as 
práticas pedagógicas adotadas pelos professores e as possibilidades de integração entre a técnica e a didática oferecendo aos docentes a oportunidade de adquirir conhecimentos em Tecnologia da Informação e as formas de introduzi-los no contexto educacional inovando o processo de ensino de sua disciplina.

Durante uma das reuniões periódicas com a coordenação de área do subprojeto Computação, os bolsistas comentaram que após a convivência com os alunos das escolas estaduais e a experiência adquirida ao assistir aulas de Matemática e Física nas diversas séries ficou constatado que existe um alto grau de dificuldade com a Tabuada, considerada elementar para o desenvolvimento dos alunos. Diante desta circunstância, foi sugerido pelo grupo de alunos que a primeira oficina temática utilizasse material concreto para contextualização deste conteúdo. Cada bolsista criou um material pedagógico para ser utilizado em oficinas temáticas antes mesmo da inclusão do computador como ferramenta de ensino e aprendizagem. Entre os materiais utilizados para confecção dos kits didáticos citam-se madeira, caneta, lápis de cor, tinta para papel, giz de cera, canetinha hidrocor, cartolina, papel vergê, E.V.A, etc.

Dada a palavra para discussão sobre o andamento das atividades do projeto PIBID os bolsitas enfatizaram a experiência adquirida com a presença dos mesmos nas escolas estaduais. Este fato foi relatado através de comentários sobre os conteúdos assistidos nas aulas das disciplinas de Matemática e Física e as observações feitas em relação à dinâmica do processo pedagógico utilizado. Muito se falou em alternativas a serem trabalhadas pelo PIBID Computação para sanar as carências de conteúdos por alguns alunos.

Os bolsistas elaboraram questionários para analisar a dimensão sócio-cultural da comunidade escolar atendida pelo projeto bem como as características das escolas, dos professores das disciplinas de Física e Matemática e dos alunos objetivando que as informações coletadas nesta ação pudessem servir como referência e planejamento da proposta pedagógica e para analisar qual a melhor forma de inserir o uso do computador no processo de ensino e aprendizagem de Física e Matemática, nas diferentes séries oferecidas pelas escolas participantes.

O questionário sócio-cultural foi respondido por 1.425 alunos das duas escolas estaduais atendidas pelo PIBID Computação, contemplando desde o $6^{\circ}$ ano do Ensino Fundamental até o $3^{\circ}$ ano do Ensino Médio. Ficou constatado que apenas 13\% dos alunos que responderam ao questionário consideram ter ótimo desempenho na disciplina de Matemática, 50\% consideram seu desempenho bom, 28\% atribuíram a classificação regular ao seu desempenho nesta disciplina e $9 \%$ consideram possuir desempenho ruim em Matemática. Em contrapartida, a tabulação dos dados demonstrou que $92 \%$ dos alunos que participaram da pesquisa indicam saber utilizar o computador.

Com base nesta pesquisa, os bolsistas fizeram um levantamento prático sobre as habilidades dos alunos com o uso do computador nas escolas estaduais atendidas pelo projeto para que este diagnóstico tecnológico pudesse ser utilizado como base para criação da proposta pedagógica para uso dos softwares educacionais.

Os dados coletados serviram como incentivo aos futuros docentes na preparação de propostas pedagógicas que abordem o enfoque técnico (sistema operacional, características dos softwares utilizados, formas de instalação e utilização) e a abordagem 
disciplinar (uso dos programas de código livre nas disciplinas do ensino fundamental e/ou médio) de diferentes softwares educacionais das áreas de Matemática e Física que poderão ser utilizados conforme avaliações de sua adequação aos objetivos curriculares. O foco da proposta não deverá ser o ensino puro de conceitos de informática e sim as habilidades a serem trabalhadas para que os alunos possam realizar atividades didáticopedagógicas através das potencialidades oferecidas pela tecnologia da informação.

\section{Resultados e discussão}

Através das constatações feitas durante a vigência do primeiro ano do projeto PIBID Computação, espera-se que este possa viabilizar as atividades didáticopedagógicas através das potencialidades oferecidas pela tecnologia da informação motivando os professores das escolas públicas na utilização dos recursos computacionais para enriquecimento dos conteúdos abordados por suas disciplinas.

Este estudo de caso demonstrou que é possível a troca de experiências entre os professores em efetivo exercício no magistério e os futuros docentes que serão formados pelo IFSULDEMINAS - Campus Machado para atuação no ensino da computação. Com a diversidade na realização das atividades práticas de ensino como componente curricular e o andamento das atividades do PIBID os alunos do curso passaram a ter uma formação sólida e abrangente como educadores, com base nas áreas técnicas de computação e com ênfase nos aspectos pedagógicos e sociais existentes na realidade das escolas públicas.

A participação dos alunos da Licenciatura em Computação na realidade das escolas estaduais vem permitindo-lhes a aquisição de experiências práticas docentes na busca constante por melhorias do processo ensino-aprendizagem. O relato destas experiências tem permitido a reflexão dos docentes do curso no direcionamento das atividades práticas como componentes curriculares. O planejamento do curso passou por reformulações quanto à distribuição destas práticas como disciplinas específicas ao longo de todos os períodos e estas alterações passam a vigorar a partir da entrada da nova turma no início de 2013.

As experiências relatadas serviram também como incentivo na busca por novos recursos didáticos e pedagógicos, como por exemplo, a elaboração de um projeto para pleitear a criação de um laboratório interdisciplinar no Campus Machado buscando atender as demandas dos docentes e discentes dos cursos de licenciatura bem como a comunidade escolar atendida pelo PIBID. Essas atividades terão o objetivo de propiciar aos licenciandos experiências interdisciplinares na sua formação inicial, como uma estratégia para o desenvolvimento de conhecimentos, habilidades e competências necessárias para que sejam capazes, como professores, de conceber atividades de ensino interdisciplinares junto aos seus alunos.

\section{Considerações finais}

Numa visão geral, a estrutura do curso de Licenciatura em Computação do IFSULDEMINAS - campus Machado possui componentes que se articulam e interagem, visando adequada formação de docentes em informática na educação: organização curricular, recursos humanos, recursos metodológicos e infraestrutura. As 
interações entre professor, aluno, conteúdo, contexto e método revelam, efetivamente, as principais finalidades educativas permitindo a formação de recursos humanos qualificados nas atividades docentes de ensino da computação, bem como na possibilidade de aplicação, projeto e construção de software educacional com objetivo de melhorar o processo de ensino-aprendizagem como também a gestão do processo educacional.

Com as experiências adquiridas na realização das práticas de ensino e pela participação no PIBID, para os alunos do curso de Licenciatura em Computação, futuros docentes, o ato de ensinar passou a ser considerado uma prática social que através da ação cultural se concretizou na interação entre professores e alunos, através da reflexão da cultura e dos contextos sociais aos quais estão vinculados. A comunidade escolar passou a indagar como não reduzir o conceito da prática educativa às simples ações de responsabilidade total e atuação do professor na sala de aula e a tentar a sistematização da dimensão real da prática educativa apontando como cada parte deste sistema pode afetar a prática na sala de aula.

As próximas etapas deste projeto são a elaboração, junto aos supervisores, do cronograma de capacitação dos professores multiplicadores da informática educativa, o acompanhamento de todas as atividades propostas e a avaliação constante para o aprimoramento da proposta pedagógica analisando-se as dificuldades e os fatores pertinentes ao atendimento de todas as atividades previstas.

\section{Referências}

Alves, R. M.; Zambalde, A. L. (2002). Internet e educação. Lavras: UFLA/FAEPE.

Freire, P. (1997). Pedagogia da autonomia: saberes necessários à prática educativa. São Paulo: Paz e Terra.

Gadotti, M. (2003). Boniteza de um sonho: Ensinar e aprender com sentido. São Paulo: GRUBHAS.

Gadotti, M. (2004). "Informação, conhecimento e sociedade em rede. Que potencialidades?” In: Fórum Paulo Freire - IV Encontro Internacional - Caminhando para uma cidadania multicultural. Universidade do Porto.

Kenski, V. M. (2010). Tecnologias e ensino presencial e a distância. São Paulo: Papirus.

Lévy, P. (1999). Cibercultura. São Paulo: Editora 34; tradução de Carlos Irineu da Costa.

Lucena, M. F. P. (1994) O uso das tecnologias da informática para o desenvolvimento da educação. Publicações técnicas. Rio de Janeiro: COPPE Sistemas/UFRJ.

Mcluhan, H. M. (1974) Os meios de comunicação como extensões do homem. São Paulo, Cultrix.

Zambalde, A. L; ALVES, R. M. (2002). Introdução à informática educativa. Lavras: UFLA/FAEPE. 